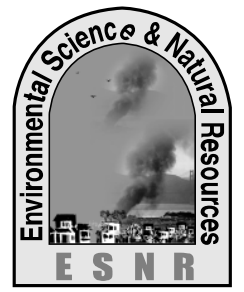

J. Environ. Sci. \& Natural Resources, 6(1): 79 - 87, 2013

ISSN 1999-7361

\title{
Effects of Climate Variables on Kala-azar Prevalence at Major Affected Districts in Bangladesh
}

\author{
M. R. Amin, S. M. Tareq and S. H. Rahman
}

Department of Environmental Sciences, Jahangirnagar University, Savar, Dhaka-1342

\begin{abstract}
An attempt was made to explore correlation between climate variables and Kala-azar prevalence at four highly affected districts in Bangladesh: Mymensingh, Tangail, Pabna, and Rajshahi. The climate variables included were temperature, rainfall and relative humidity. With the rise of yearly average humidity in Mymensingh, Tangail and Rajshahi districts Kala-azar prevalence was significantly increased and with the rise of yearly total rainfall positive but not significant correlation was observed in Mymensingh,Tangail and Rajshahi. In Mymensingh negative correlation was found with yearly average maximum and minimum temperature. Positive association with yearly total rainfall in Mymensingh, Pabna \& Rajshahi and yearly average minimum temperature in Rajshahi and yearly average maximum temperature in Tangail was observed. The prevalence of the disease was found to have negative correlation with yearly average maximum temperature in both Pabna \& Rajshahi, yearly average minimum temperature in both Tangail \& Pabna and yearly total rainfall in Tangail.
\end{abstract}

Key Words: Climate Variables, Kala-azar, Environmental variation

\section{Introduction}

The global climate change is one of the most significant environmental issues of the present world (Chowdhury and Debsharma, 1992).Climate change is a reality and no longer a future concern, now it is evident from scientific study that our mother climate has undergone an abnormal human induced change, various climatic parameters such as rainfall, temperature, humidity, sunshine hour etc. of various regions of the world have shown significant trends (Burton, 1997). Ericksen et al (1996) has reported that since climate change is a dynamic phenomenon, changes will occur over time, and implications will only be understood in future, it is not possible 'to define a changing climate' that might occur 'within a defined period in future'.

Climate change means a change of climate which is attributed directly or indirectly alters the composition of the global atmosphere and which is in addition to natural climate variability observe over comparable time period (Smith et al., 1996). Temperature depends on radiation, cloud cover and humidity. Humidity indicates the amount of water in vapor form in the atmosphere. Precipitation measures the amount of water in its liquid or solid phase.

There are direct causal connections between climatic factors and human biology, climatic factors may disturb earth's physical systems and ecosystems; these disturbances, in turn, pose a direct and indirect risk to human health, so, the distribution and abundance of pathogens may be determined by various climatic factors, e.g. temperature, humidity, rainfall, sunshine, wind, atmospheric pressure, etc(IPCC, 2007).

Visceral Leishmaniasis (VL) commonly known as Kala-azar was prevailing in Bangladesh as one of the public health problem up to late 1950(WHO, 2003).
The disease almost disappeared due to the effect of DDT spraying on the sand fly vector in early 1960; historically Kala-azar is endemic in Bangladesh. In the sixties and very early seventies DDT spraying under the malaria eradication programme successfully controlled VL transmission in Bangladesh, in the late 1970s, Kala-azar reappeared in Bangladesh sporadically, since then Kala-azar cases have been increasing and from 8 upazilla reporting Kala-azar during 1981-85 period (Napier, 1996). At present Kala-azar cases reported from 139 upazillas in 45 districts of Bangladesh. More than half of total cases (54\%) are from Mymensingh districts. Another 3 districts Pabna, Tangail and Jamalpur will add 25\% cases. The disease pattern is extremely focal with most cases reported from rural areas, exhibiting a familial and contiguous household clustering pattern among the lower socio-economic groups (Martens, et $a l ., 1995)$. Kala-azar is caused by Leishmania parasite and transmitted by phlebotomine sand flies. Kala-azar is a climate-sensitive disease basically due to preferred breeding of sand fly vectors in alluvial soil with high sub-soil water table, distributed in temperatures ranging from 7 to $37^{\circ} \mathrm{C}$, and Relative Humidity (RH) above 70\%. Thomson et al (1999) have mapped the distribution of Phlebotomus orientalis and found that mean annual maximum temperature and soil type were the determining factors for distribution. The life cycle of sand flies is also influenced by $\mathrm{RH}$ and temperature resulting in fluctuations in density (Dhanda et al., 1982). As climate-related changes in life-cycle dynamics of pathogens may increase or decrease the potential rate of transmission of disease (Githeko et al, 2000). So, it is important to correlate between climate variables and Kala-azar prevalence. This paper presented a study conducted on effects of climate variables on 
Kala-azar prevalence at major affected districts in Bangladesh using data from 1987-2000.

\section{Materials and methods}

Month wise data of climate variables i e, temperature, rainfall and relative humidity over the period 1987 2000 for highly affected districts in Bangladesh: Mymensingh, Pabna ,Tangail and Rajshahi were collected from Bangladesh Meteorological Department and converted into yearly maximum and minimum average temperature, yearly total rainfall and yearly average relative humidity. Climate variables of Ishwardi meteorological station were used for Pabna. District wise data of Kala-azar incidence for these districts during the period were also collected from MIS, DGHS, Mohakhali, Dhaka.
Climate factors such as yearly maximum and minimum average temperature, yearly total rainfall, yearly average relative humidity and Kala-azar incidence were compared and analyzed. To find the association between Kala-azar incidence and climate change factors the Pearson's correlation was applied.

\section{Results and Discussions}

Variability of climatic parameters in Mymensingh: Effects on Kala-azar incidence Kala-azar statistics: Kala-azar cases are marked by an increasing trend over the period 1987-2000 and highest incidences (4315) were observed in 2000.Climate variables (temperature, rainfall and humidity) are important for sandfly activity and Kala-azar epidemiology.

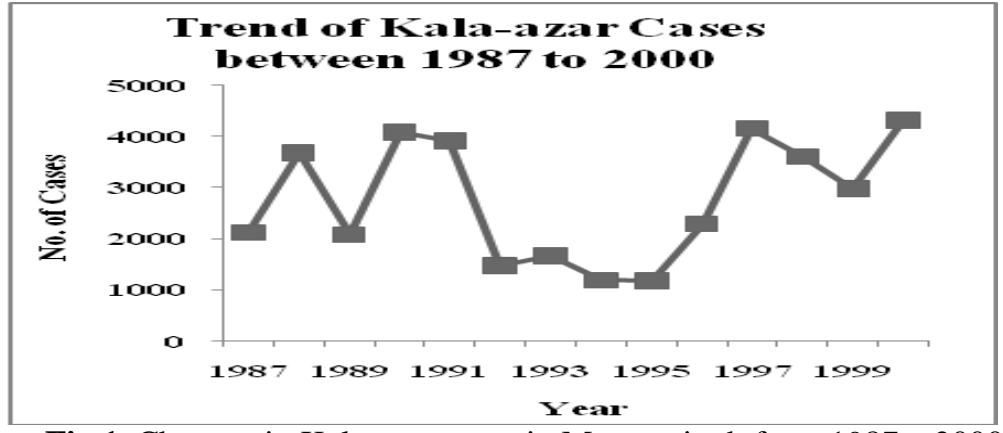

Fig 1. Changes in Kala-azar cases in Mymensingh from 1987 - 2000

\section{Statistics of Climatic parameters}

Yearly average maximum temperature increases by $0.001^{\circ} \mathrm{C}$ per annum and per annum estimated regression of annual minimum temperature over the period from 1987-2000 is marked by increasing trend of $0.055^{\circ} \mathrm{C}$. Yearly total rainfall decreases by $3.72 \mathrm{~cm}$. The highest yearly total rainfall $(283 \mathrm{~cm})$ was in 1988 and the lowest annual total rainfall $(132 \mathrm{~cm})$ was observed in 1992. The yearly average relative humidity is marked by an increasing trend of $0.09 \%$ during the study period. The highest annual average relative humidity (83\%) was in 2000 and the lowest (76\%) was in 1994 and 1995.

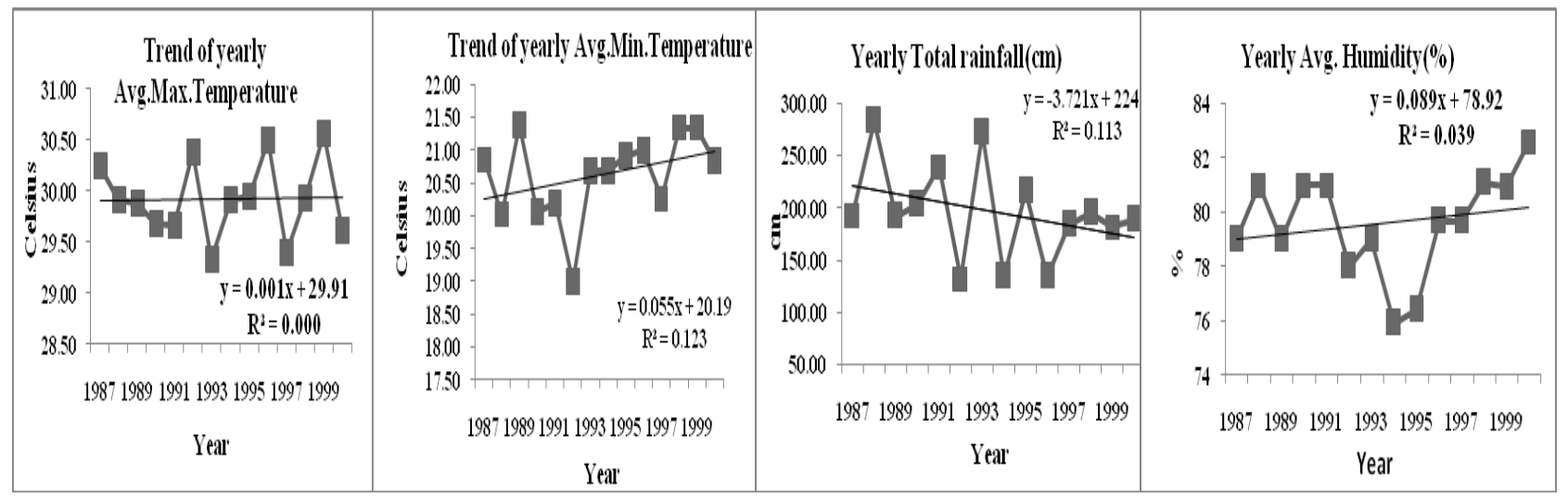

Fig. 2. Regression of yearly Avg. max. temperature, yearly Avg. min. temperature, yearly total rainfall and yearly average humidity.

\section{Correlation between Climate Parameters and Kala- azar incidence}

Correlation coefficients have been calculated between climate factors i.e. annual average maximum temperature, annual average minimum temperature, 
annual average total rainfall and annual average humidity, and Kala-azar. In the study area, Kala-azar were found to have negative correlation with annual average maximum temperature (-0.36) and annual average minimum temperature $(-0.06)$, and to have positive correlation with annual total rainfall $(+0.29)$ and annual average humidity $(+0.88)$.

Table 1. Results of correlation analysis on Kala-azar and climate factors of Mymensingh district are shown below.

\begin{tabular}{|c|l|c|}
\hline \multicolumn{2}{|c|}{ Climate variables } & Value of Correlation Coefficient \\
\hline \multirow{3}{*}{$\mathrm{n}=14$} & Annual average maximum temperature & -0.36 \\
\cline { 2 - 3 } & Annual average minimum temperature & -0.06 \\
\cline { 2 - 3 } & Annual total rainfall & +0.29 \\
\cline { 2 - 3 } & Annual average humidity & +0.88 \\
\hline
\end{tabular}

The trends of Kala-azar and climate variables for the period of 1987-2000 are also shown in graphical presentation. The following graphs represent positive

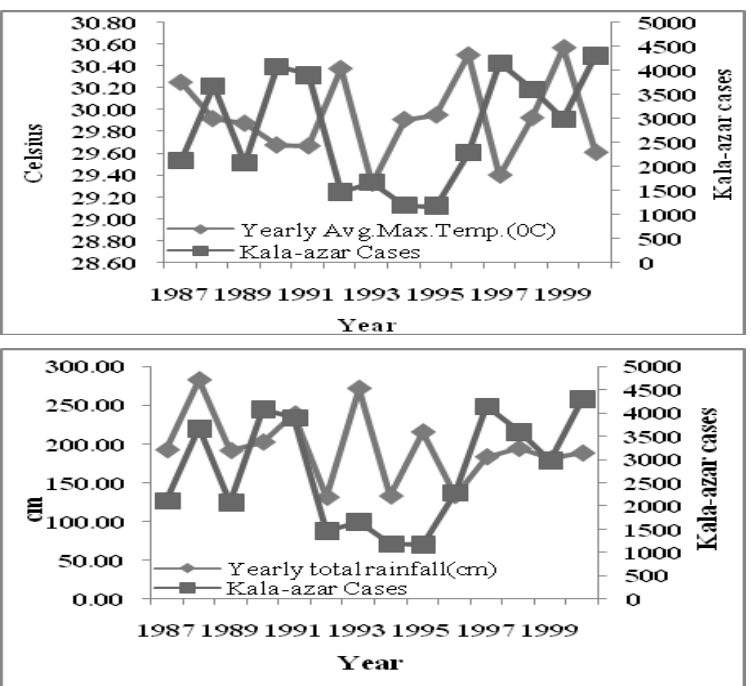

correlation between Kala-azar and annual total rainfall, annual average humidity.

Fig.3. Trend of climate variables and Kala-azar cases in Mymensingh for the period of 1987-2000

\section{Variability of climatic parameters in Mymensingh}

\section{Kala-azar statistics}

In the district, Kala-azar shows increasing trend during 1987-2000.However, the increasing trend was sometime relatively sharp and sometime gradual. A

during the period. The highest incidences (976) were observed in 1998 and the lowest incidences were in significant fluctuation in Kala-azar was observed 1987.

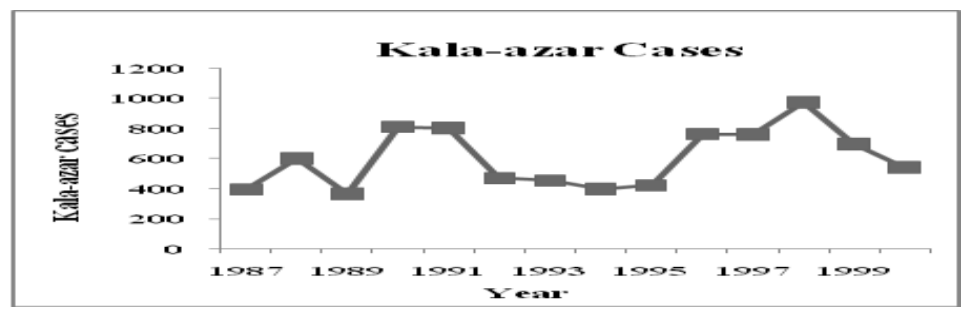

Fig.4. Changes in Kala-azar cases in Tangail from 1987 - 2000 


\section{Climate Statistics}

Regression of annual maximum temperature for the period 1987-2000 shows an average rise of $0.06^{\circ} \mathrm{C}\left(\right.$ Fig.5) and the highest temperature $\left(31.00^{\circ} \mathrm{C}\right)$ was in 1994,1996 and 1999 and the lowest annual maximum temperature $\left(29.00^{\circ} \mathrm{C}\right)$ was observed in 1993.The annual minimum temperature is also found by an increasing trend of $0.04^{\circ} \mathrm{C}$ during the period. The lowest $\left(18.99^{\circ} \mathrm{C}\right)$ and the highest $\left(21.39^{\circ} \mathrm{C}\right)$ annual minimum temperature were in 1992 and 1989 respectively.

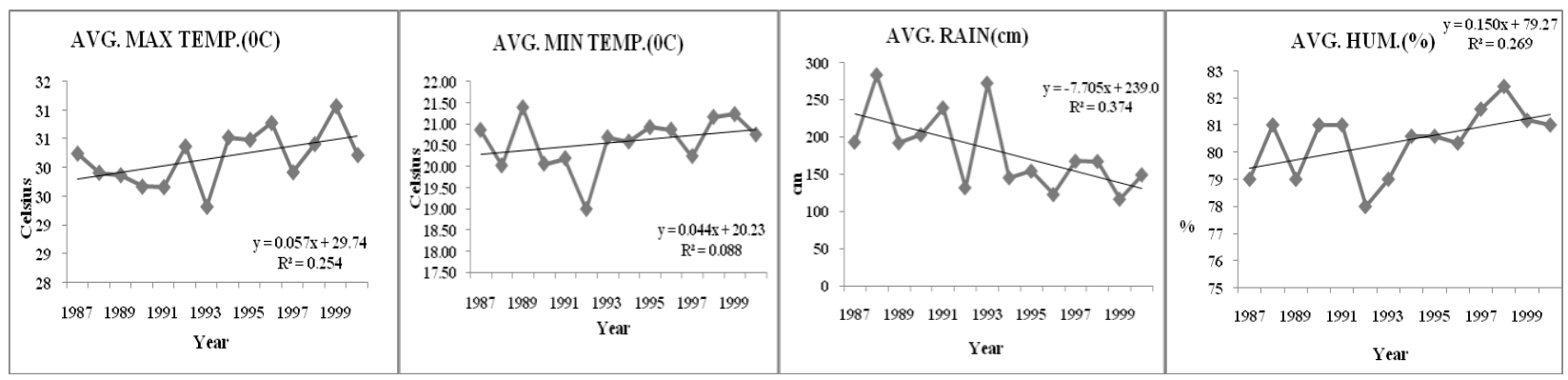

Fig. 5. Trend of Climate variables in Tangail from $1987-2000$

Annual total rainfall has shown a decreasing trend over the study period from 1987-2000 (Fig.5).The estimated simple regression of yearly total rainfall shows an average annual decrease of $7.70 \mathrm{~cm}$ over the mentioned period. The highest yearly total rainfall $(283 \mathrm{~cm})$ and the lowest $(116.75 \mathrm{~cm})$ were observed in 1988 and 1999 respectively. It is found that humidity have increased with a rate of $0.15 \%$ per annum. Over the study period, the highest difference, $4 \%$ was observed between the highest and the lowest yearly average humidity
Correlation between Climate variables and Kalaazar incidence

Table 2 presents that Kala-azar is positively correlated with 2 climate factors out of used 4 . Kalaazar incidences were found to be positively correlated $(+0.04)$ with annual average maximum temperature and annual average humidity $(+0.74)$ over the period. The negative correlation $(-0.03)$ of Kala-azar was observed with annual total rainfall and annual average minimum temperature.

Table 2. Results of correlation analysis between climates related variables and Kala-azar cases of study area Tangail

\begin{tabular}{|l|l|c|}
\hline \multicolumn{2}{|c|}{ Climate variables } & Value of Correlation Coefficient \\
\hline \multirow{3}{*}{$\mathrm{n}=14$} & Annual average maximum temperature & +0.04 \\
\cline { 2 - 3 } & Annual average minimum temperature & -0.03 \\
\cline { 2 - 3 } & Annual total rainfall & -0.03 \\
\cline { 2 - 3 } & Annual average humidity & +0.74 \\
\hline
\end{tabular}

The trends of Kala-azar and climate parameters for the period of 1987-2000 are also shown in graphical presentation.
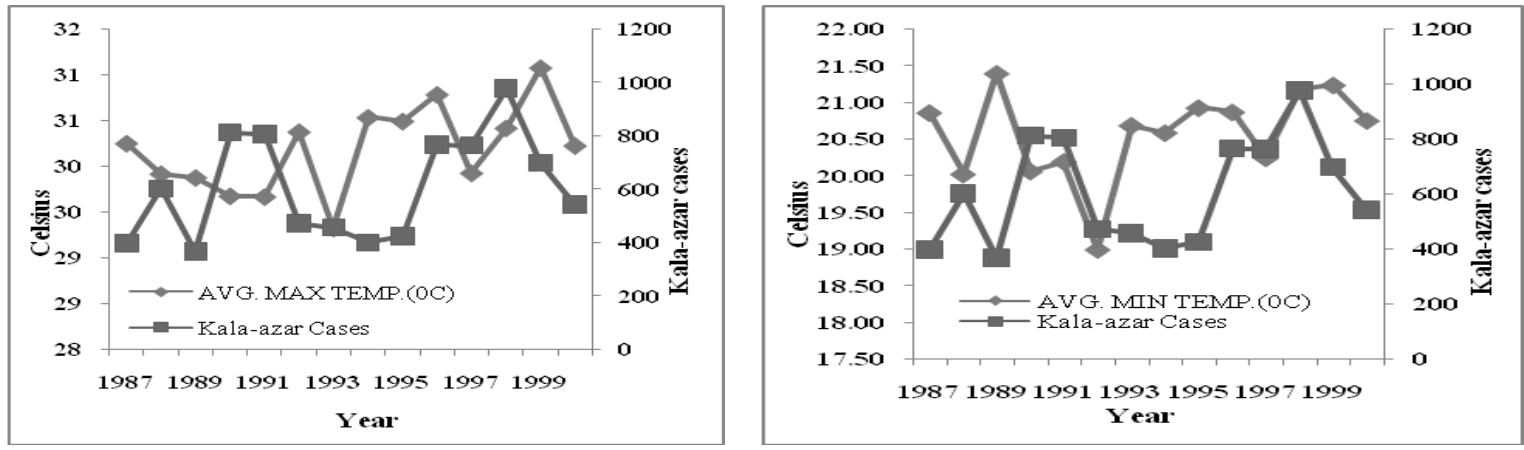

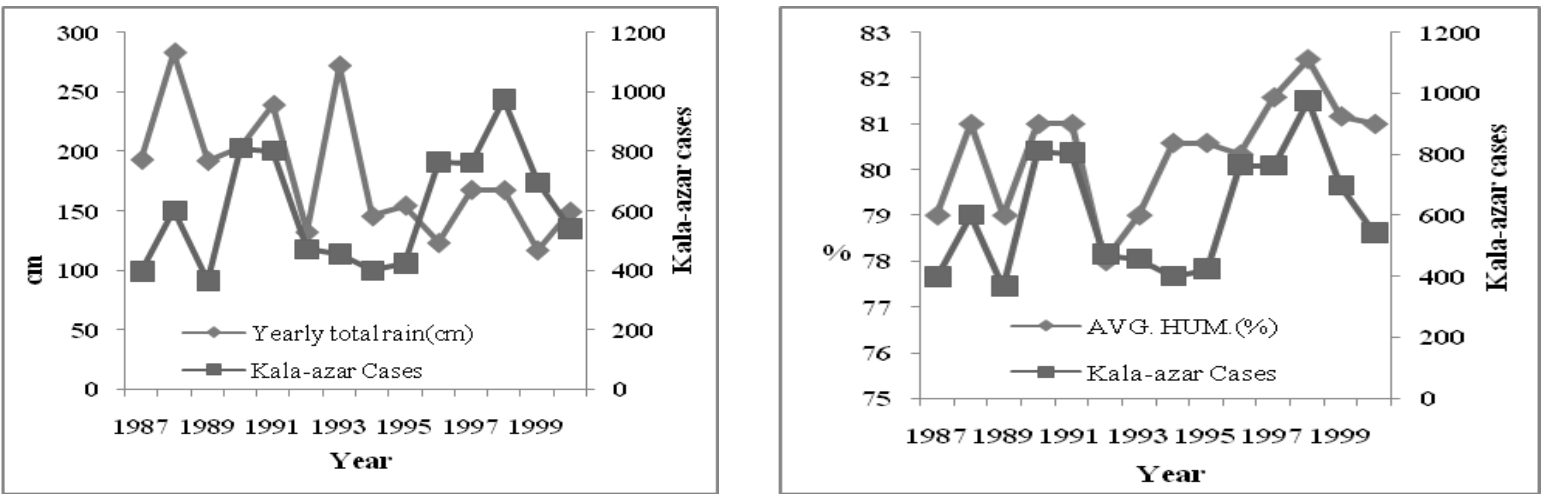

Fig. 6: Trend of climate variables and Kala-azar incidences in Tangail for the period of 1987-2000

Variability of climatic parameters in Pabna: Effects on Kala-azar prevalence

Kala-azar statistics

Kala-azar cases are marked by decreasing trend over the period 1987-2000 and highest incidences (2023) and lowest (889) were observed in 1990 and

1992.Climate variables (temperature, rainfall and humidity) are important for sandfly activity and Kalaazar epidemiology.

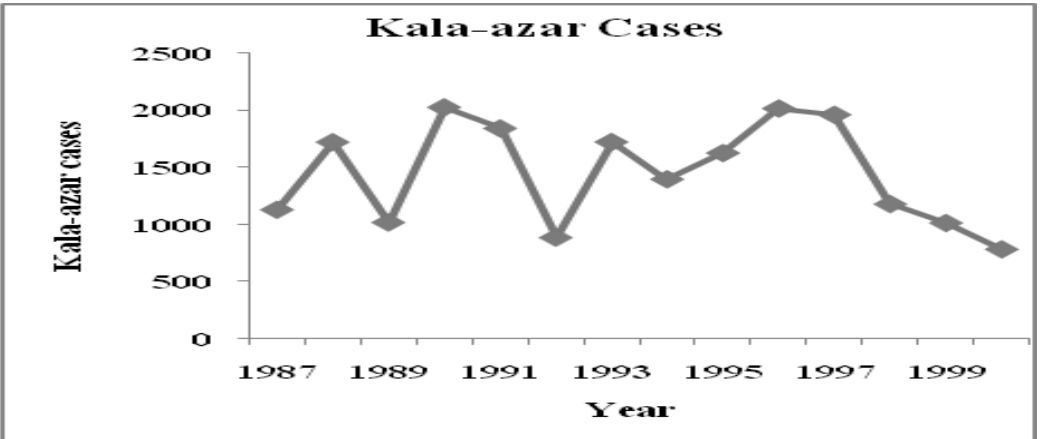

Fig.7. Changes in Kala-azar cases in Pabna from 1987 - 2000

\section{Climate Statistics}

Regression of annual maximum temperature for the period 1987-2000 shows an average decrease of 0.02 ${ }^{\circ} \mathrm{C}\left(\right.$ Fig.8) and the highest temperature $\left(31.49^{\circ} \mathrm{C}\right)$ was in 1987 and 1999 and the lowest annual maximum temperature $\left(30.42^{\circ} \mathrm{C}\right)$ was observed in 1990.The annual minimum temperature is also found by an increasing trend of $0.07^{\circ} \mathrm{C}$ during the period. The lowest $\left(19.46^{\circ} \mathrm{C}\right)$ and the highest $\left(21.23^{\circ} \mathrm{C}\right)$ annual minimum temperature were in 1989 and 1999 respectively. Annual total rainfall has shown an increasing trend over the study period from 1987-

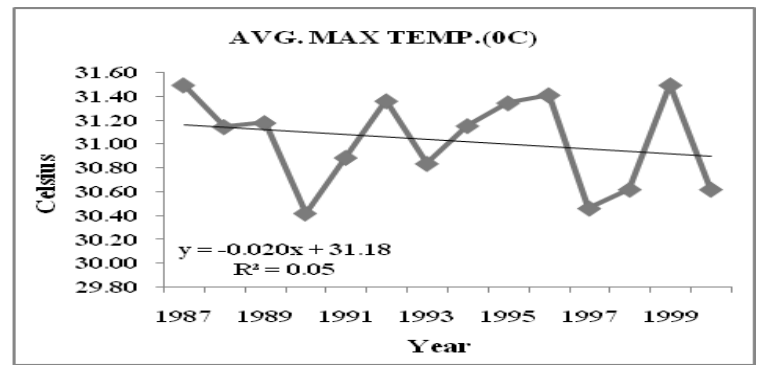

2000 (Fig.8).The estimated simple regression of yearly total rainfall shows an average annual increase of $0.89 \mathrm{~cm}$ over the mentioned period. The highest yearly total rainfall $(175 \mathrm{~cm})$ and the lowest $(88.00$ $\mathrm{cm})$ were observed in 1990 and 1994 respectively. It is found that humidity have increased with a rate of $0.19 \%$ per annum. Over the study period, the highest difference, $7 \%$ was observed between the highest and the lowest yearly average humidity.

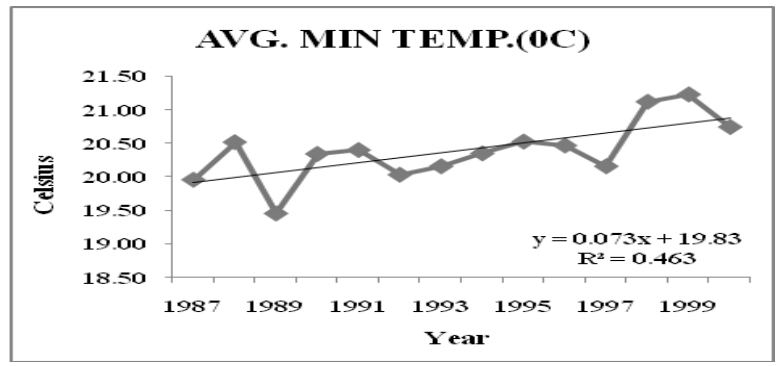



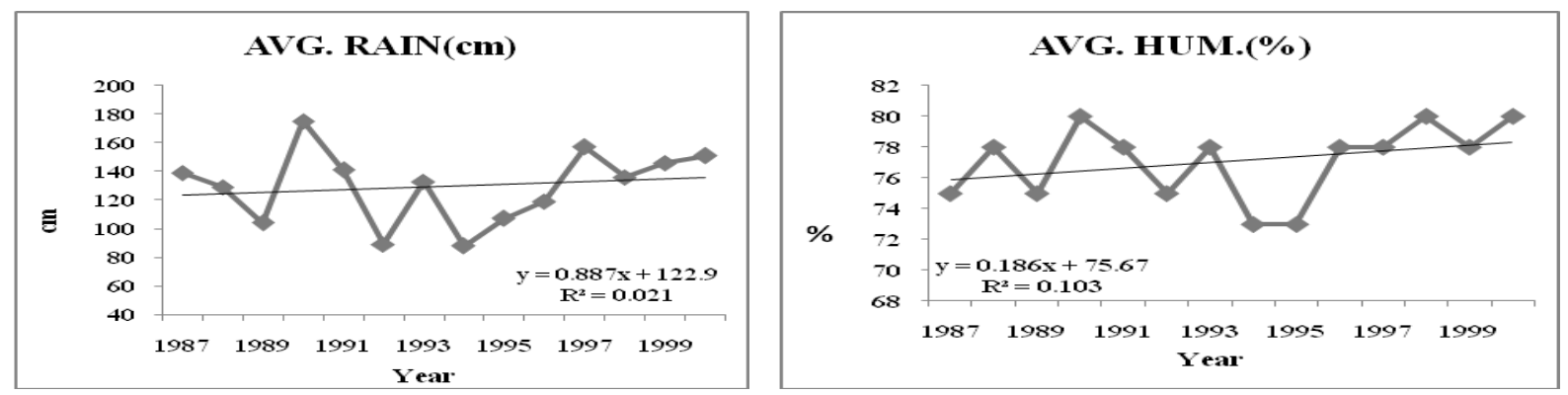

Fig. 8. Trend of Climate variables in Pabna from 1987 - 2000

\section{Correlation between Climate variables and Kala-azar prevalence}

Table 3 presents that Kala-azar is positively correlated with 2 climate factors out of used 4 . Kalaazar prevalence were found to be positively correlated $(+0.31)$ with annual total rainfall and annual average humidity $(+0.19)$ over the period. The negative correlation $(-0.30)$ of Kala-azar was observed with annual average maximum temperature and annual average minimum temperature $(-0.06)$.

Table 3. Results of correlation analysis between climate related variables and Kala-azar cases of study area Pabna

\begin{tabular}{|c|l|c|}
\hline \multicolumn{2}{|c|}{ Climate variables } & Value of Correlation Coefficient \\
\hline \multirow{3}{*}{$\mathrm{n}=14$} & Annual average maximum temperature & -0.30 \\
\cline { 2 - 3 } & Annual average minimum temperature & -0.06 \\
\cline { 2 - 3 } & Annual total rainfall & +0.31 \\
\cline { 2 - 3 } & Annual average humidity & +0.19 \\
\hline
\end{tabular}

The trends of Kala-azar and climate parameters for the period of 1987-2000 are also shown in graphical presentation.
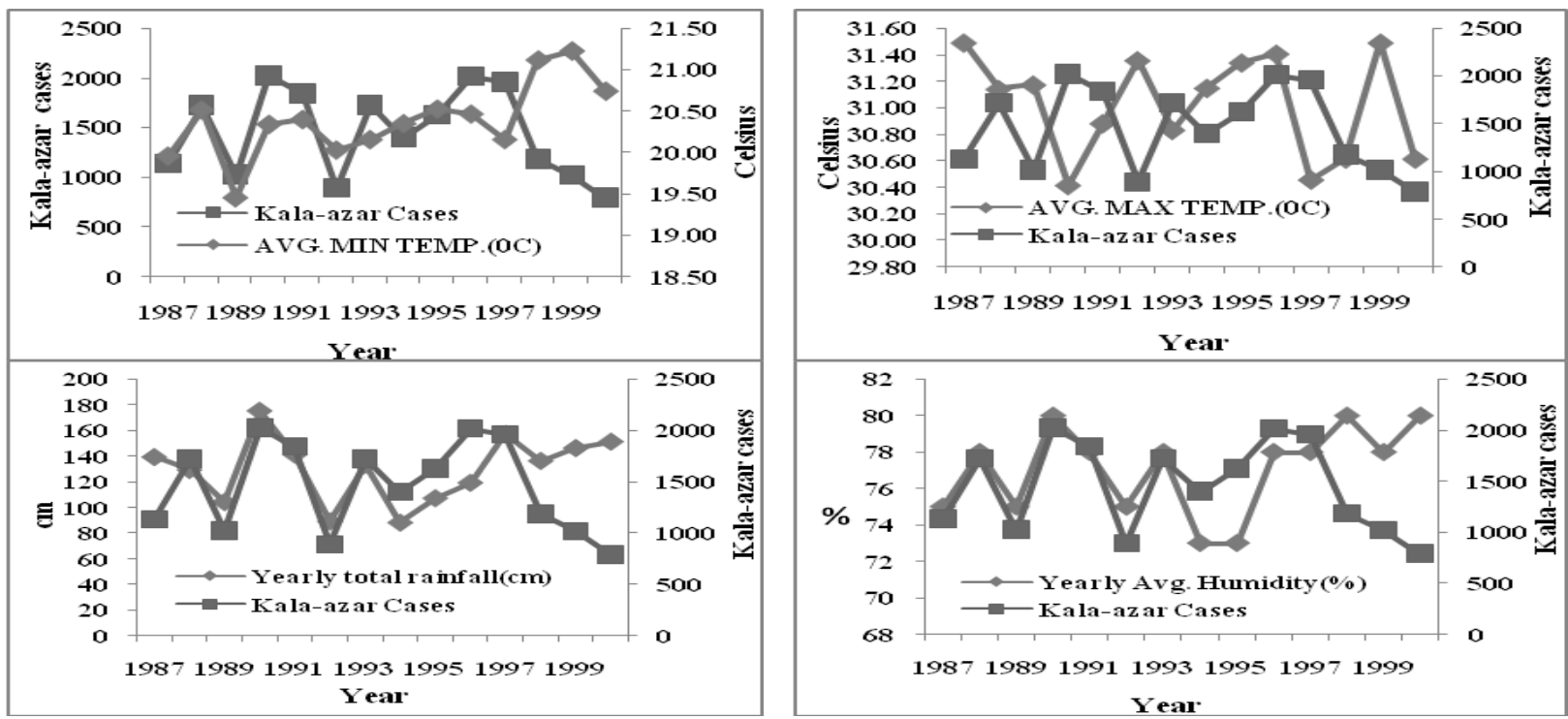

Fig. 9: Trend of climate variables and Kala-azar incidences in Pabna for the period of 1987-2000

\section{Climate change and climate variability in Rajshahi district: Effects on Kala-azar prevalence}

\section{Disease statistics}

In the district, Kala-azar case is marked by an increasing trend over the period 1987-2000 and the highest cases (1032) and the lowest (401) were observed in 1998 and 1999 


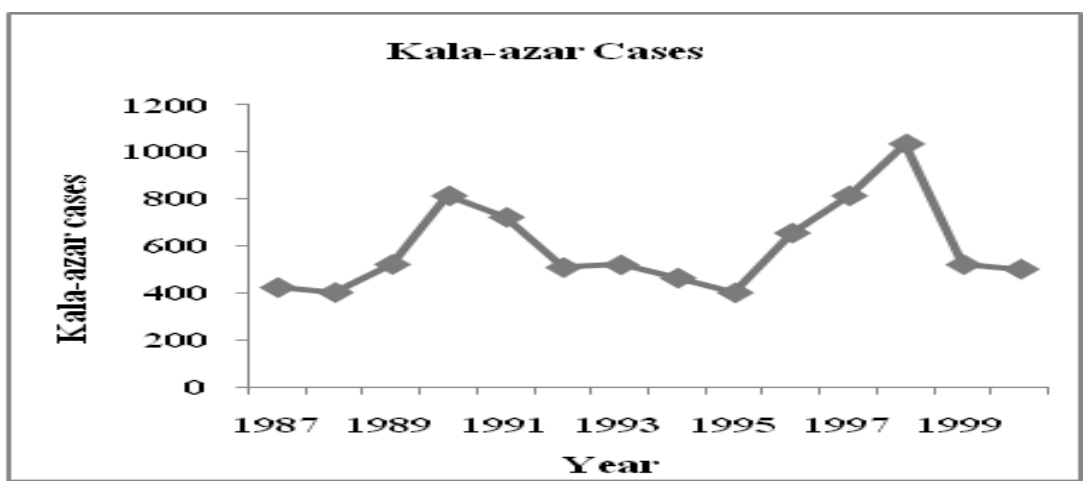

Fig 10. Trend of Kala-azar cases in Rajshahi

\section{Climate Statistics}

Estimated regression of annual maximum temperature over the period from 1987-2000 reflects an average

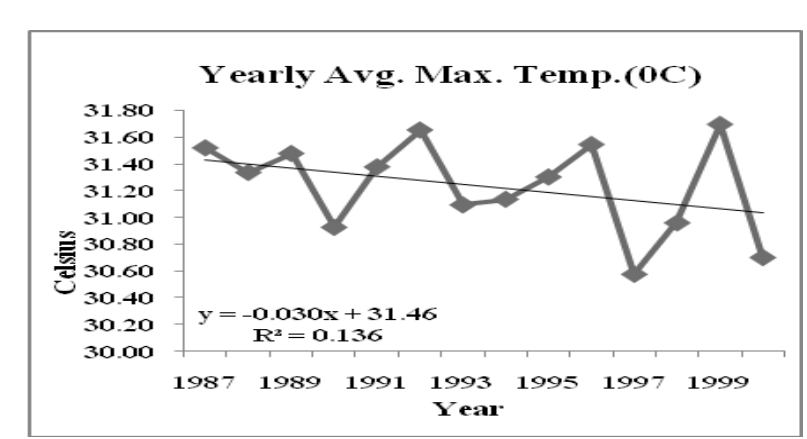

decrease of $0.03^{\circ} \mathrm{C}$ per annum (Fig. 11).The annual minimum temperature is marked by increasing trend of $0.08^{\circ} \mathrm{C}$ over the years.

Fig 11. Trends of annual average maximum and minimum temperature

Annual total rainfall increases by $1.87 \mathrm{~cm}$. The highest annual total rainfall $(155 \mathrm{~cm})$ was observed in 1999 and the lowest average rainfall $(70 \mathrm{~cm})$ was in 1992(Fig.12). The Fig.12 shows that the highest annual average relative humidity $(81 \%)$ was in 1990 ,

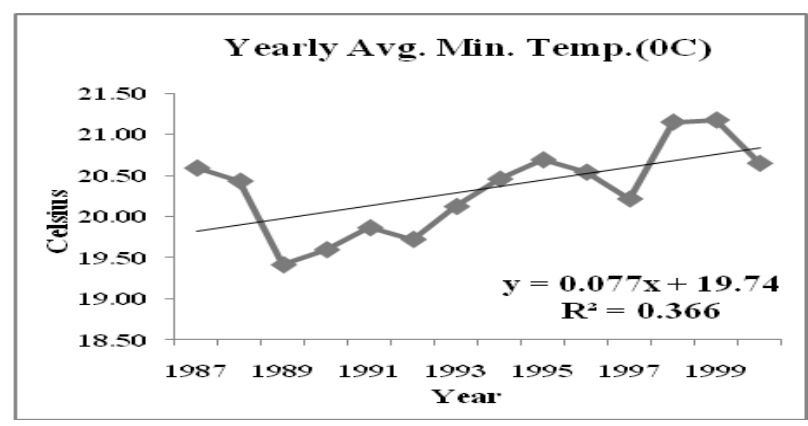

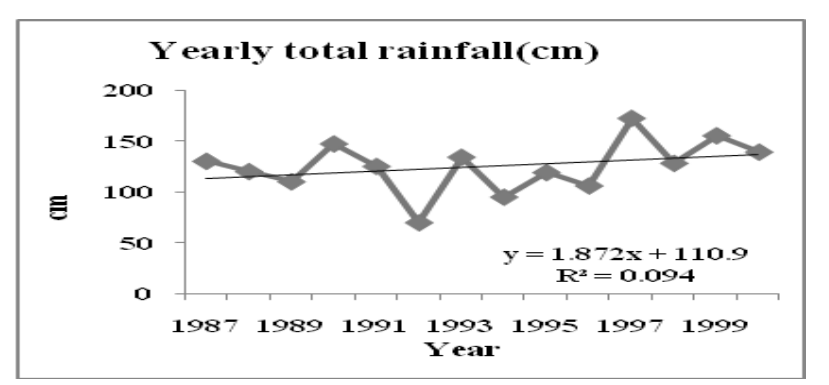

1998, 2000 and 2000 and on the other hand, the lowest $(74 \%)$ was in 1994 .The yearly average relative humidity is marked by an increasing trend of $0.25 \%$ during the study period

Fig 12. Regression of yearly total rainfall and yearly average humidity

\section{Correlation between climates related variables and Kala-azar cases}

Kala-azar prevalence were found to have positive correlation with annual average humidity $(+0.69)$, annual average rainfall $(+0.35)$ and to have negative correlation with annual average minimum temperature (-0.02), annual average maximum temperature (-0.45). 
Table 4. Results of correlation analysis on Kala-azar cases and climate factors of Rajshahi district are shown below.

\begin{tabular}{|l|l|c|}
\hline \multicolumn{1}{|c|}{ Climate variables } & Value of Correlation Coefficient \\
\hline \multirow{3}{*}{$\mathrm{n}=14$} & Annual average maximum temperature & -0.45 \\
\cline { 2 - 3 } & Annual average minimum temperature & -0.02 \\
\cline { 2 - 3 } & Annual total rainfall & +0.35 \\
\cline { 2 - 3 } & Annual average humidity & +0.69 \\
\hline
\end{tabular}

The trends of Kala-azar prevalence and climate variables for the period of 1987-2000 are also shown in graphical presentation.
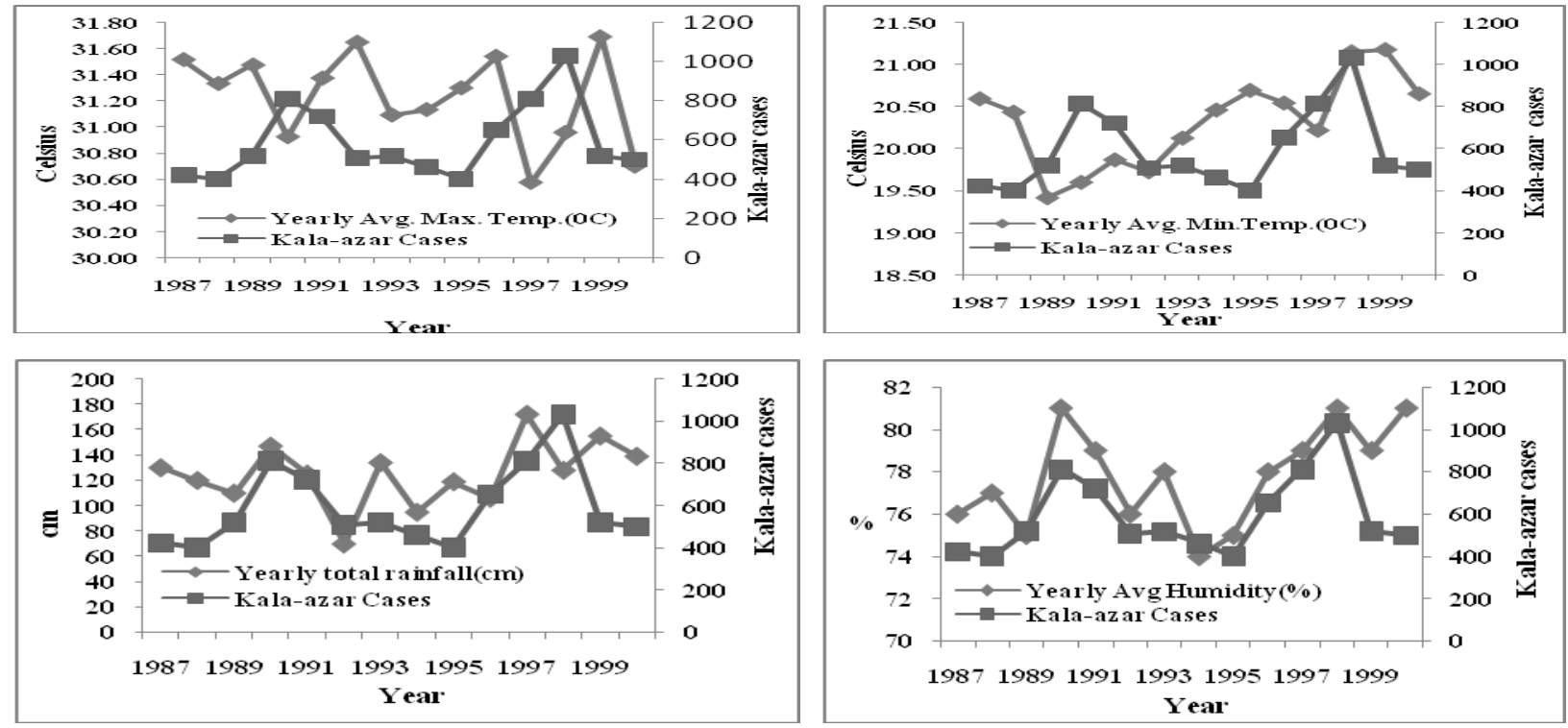

Fig 13. Trend of climate variables and Kala-azar prevalence in Rajshahi for the period of 1987-2000

\section{Conclusion}

Considering all other factors (non-climatic) remaining as it is, it can be concluded that the correlation coefficients between climate factors and Kala-azar incidence varied among the study areas. Kala-azar prevalence was found to have positive correlation with yearly average humidity and negative correlation with yearly average minimum temperature in all study areas i.e, Mymensingh, Tangail, Pabna \& Rajshahi districts. While yearly total rainfall in both Pabna \& Rajshahi, yearly average maximum temperature in Tangail were observed to be positively correlated with Kala-azar prevalence. Kala-azar incidence was negatively correlated with yearly average maximum temperature in Mymensingh, Pabna \& Rajshahi and yearly total rainfall in Tangail.

\section{References}

Burton, I., 1997, 'Vulnerability and Adaptive Response in the Context of Climate and Climate Change', Climatic Change 36, 185-196

Chowdhury, M. H. K. and Debsharma, S. K. 1992. "Climate change in Bangladesh - A statistical review", Report on IOC-UNEP Workshop on Impacts of Sea Level Rise due to Global Warming, NOAMI, held during 16-19 November 1992, Bangladesh)

Dhanda, V.; Shetty, P. S and Dhiman R. C, 1982. Studies on phlebotomine sand flies as vectors of Kala-azar in Bihar. Proc Indo UK Workshop on Kala-azar (ICMR). 128-137

Ericksen, N. J.; Ahmad, Q. K. and Chowdhury, A. R. 1996. Socio-economic Implications of Climate Change for Bangladesh, in R.A. Warrick and Q.K. Ahmad (eds), The Implications of Climate and Sea-level Change for Bangladesh, Kluwer Acedemic Publishers, Dordrecht, pp. 205-287.

Githeko, A.; Lindsay, S.; Confalonieri, U. and Patz, J. 2000.Climate change and vector-borne diseases: a regional analysis. Bull World Health Organ, 78: 200-207.

IPCC, 2007. Summary for policymakers.In Climate Change 2007: the Physical Science Basis (eds Solomon, S. D. et al.), Cambridge University Press, Cambridge, UK. 
Martens, W. J. M.; Jetten, T. H. 1995. Climate change and vector-borne diseases: A global modeling perspective. Global Environmental Change, 5(3):195-209.

Napier, L. E. 1996. An epidemiological consideration of the transmission of Kala - azar in India. In Reports of the Kala-azar commission, India, Report no 1 (1924-25). Indian Medical Research Memories, Memoir No-4. pp 219265.November, 4 -6: 102.

Smith, J. B.; Bhatti, N.; Menzhulin, G.; Benioff, R.; Campos, M.; Jallow, B.; Rijsberman, F.; Budyko, M. I. and Dixon, R. K (eds) 1996. Adapting to Climate Change: An International
Perspective. New York: Springer-Verlag. 476p.

Thompson, M. C.; Elnaiem, D. A.; Ashford, R. W, and Connor, S. J. 1999. Towards a kala azar risk map for Sudan: map ping the potential distribution of Phlebotomus orientalis using digital data of environmental variables. Trop Med Int Health 4:105-13.

World Health Organization (WHO). Climate change impacts on health. Available at http://www.who.int/mediacentre/news/releases/ 2003/pr91/en/ 